\title{
Drug-induced Brugada-type Electrocardiogram: A Cause of Sudden Death in Patients with Schizophrenia?
}

\author{
Hideki Itoh \\ Key words: Brugada syndrome, sudden death, schizophrenia, carbamazpine
}

(Intern Med 56: 2969-2970, 2017)

(DOI: 10.2169/internalmedicine.9087-17)

Schizophrenia is a mental disorder associated with a potential risk of sudden death. Furthermore, we have to take account of antipsychotic drugs as a major cause of sudden death in these patients (1). Some antipsychotic drugs (e.g., tricyclic antidepressants and thioridazine) have been reported to cause QT prolongation and/or torsade de pointes, which are induced by blocking of the rapidly activated delayed rectifier potassium channel, $I_{\mathrm{Kr}}(2-4)$. Physicians need to be aware of the QT interval before treating patients with these drugs because patients with excessive QT prolongation may have mild phenotypes, even without culprit drugs (5).

Carbamazepine, an antiepileptic drug, has been also reported as a cause of sudden death; possibly because it blocks both the neuronal and the myocardial voltage-gated sodium channels $(6,7)$. The blocking of the cardiac sodium channel potentially causes not only conduction diseases $(8,9)$, but also "Brugada-type electrocardiography (ECG)" (10) which is characterized as a unique finding in Brugada syndrome. This syndrome is an inherited arrhythmogenic syndrome that is characterized as an ST-segment elevation in the right precordial leads and a cause of nocturnal sudden death (11). Genetic studies sometimes reveal a SCN5A mutation in patients with Brugada syndrome or patients with drug-induced Brugada ECG (12). Sodium channel blockers can lead to Brugada-type ECG, even in subjects with a normal ECG at baseline (13), and carbamazepine may also have the potential to provoke Brugada-type ECG. Ota et al. (14) showed an interesting case in which the levels of the Brugada-type ST-segment corresponded to a concentration of carbamazepine that was within the normal range and in which the ECG findings improved after the withdrawal of carbamazepine.

In order to prevent sudden death in patients with schizophrenia who are undergoing drug treatment, it may be necessary to carefully manage both QT prolongation and Brugada-like ST-segment elevation. Nevertheless it remains unknown whether drug-induced Brugada-type ECG is associated with a risk of sudden cardiac death. According to a consensus report (15), implantable cardioverter defibrillator therapy is not recommended in asymptomatic Brugada patients with drug-induced type I ECG. The most important issue is to investigate whether drug-induced Brugada-type ECG is correlated with sudden death in schizophrenia patients who are undergoing medical therapy $(16,17)$.

The author states that he has no Conflict of Interest (COI).

\section{References}

1. Ray WA, Chung CP, Murray KT, Hall K, Stein CM. Atypical antipsychotic drugs and the risk of sudden cardiac death. N Engl J Med 360: 225-235, 2009.

2. Reilly JG, Ayis SA, Ferrier IN, Jones SJ, Thomas SH. QTcinterval abnormalities and psychotropic drug therapy in psychiatric patients. Lancet 355: 1048-1052, 2000.

3. Wenzel-Seifert K, Wittmann M, Haen E. QTc prolongation by psychotropic drugs and the risk of Torsade de Pointes. Dtsch Arztebl Int 108: 687-693, 2011.

4. Itoh H, Sakaguchi T, Ding WG, et al. Latent genetic backgrounds and molecular pathogenesis in drug-induced long-QT syndrome. Circ Arrhythm Electrophysiol 2: 511-523, 2009.

5. Itoh $\mathrm{H}$, Crotti L, Aiba $\mathrm{T}$, et al. The genetics underlying acquired long QT syndrome: impact for genetic screening. Eur Heart J 37: 1456-1464, 2016.

6. Bardai A, Blom MT, van Noord C, Verhamme KM, Sturkenboom MC, Tan HL. Sudden cardiac death is associated both with epilepsy and with use of antiepileptic medications. Heart 101: 17-22, 2015.

7. Nilsson L, Bergman U, Diwan V, Farahmand BY, Persson PG, Tomson T. Antiepileptic drug therapy and its management in sudden unexpected death in epilepsy: a case-control study. Epilepsia 42: 667-673, 2001.

8. Hamilton DV. Carbamazepine and heart block. Lancet 1: 1365, 1978.

9. Herzberg L. Carbamazepine and bradycardia. Lancet 1: 10971098, 1978. 
10. Ishizue N, Niwano S, Saito $M$, et al. Polytherapy with sodium channel-blocking antiepileptic drugs is associated with arrhythmogenic ST-T abnormality in patients with epilepsy. Seizure 40: 8187, 2016.

11. Brugada P, Brugada J. Right bundle branch block, persistent ST segment elevation and sudden cardiac death: a distinct clinical and electrocardiographic syndrome. A multicenter report. J Am Coll Cardiol 20: 1391-1396, 1992.

12. Turker I, Makiyama T, Vatta M, et al. A Novel SCN5A mutation associated with drug induced Brugada type ECG. PLoS One 11: e 0161872, 2016.

13. Brugada R, Brugada J, Antzelevitch $C$, et al. Sodium channel blockers identify risk for sudden death in patients with STsegment elevation and right bundle branch block but structurally normal hearts. Circulation 101: 510-515, 2000.

14. Ota H, Kawamura Y, Sato N, Hasebe N. A carbamazepine-induced Brugada-type electrocardiographic pattern in a patient with schizophrenia. Intern Med 56: 3047-3050, 2017.
15. Priori SG, Wilde AA, Horie M, et al. HRS/EHRA/APHRS expert consensus statement on the diagnosis and management of patients with inherited primary arrhythmia syndromes: document endorsed by HRS, EHRA, and APHRS in May 2013 and by ACCF, AHA, PACES, and AEPC in June 2013. Heart Rhythm 10: 1932-1963, 2013.

16. Konigstein M, Rosso R, Topaz G, et al. Drug-induced Brugada syndrome: Clinical characteristics and risk factors. Heart Rhythm 13: 1083-1087, 2016.

17. Blom MT, Cohen D, Seldenrijk A, et al. Brugada syndrome ECG is highly prevalent in schizophrenia. Circ Arrhythm Electrophysiol 7: 384-391, 2014.

The Internal Medicine is an Open Access article distributed under the Creative Commons Attribution-NonCommercial-NoDerivatives 4.0 International License. To view the details of this license, please visit (https://creativecommons.org/licenses/ by-nc-nd/4.0/).

(C) 2017 The Japanese Society of Internal Medicine Intern Med 56: 2969-2970, 2017 